\title{
Immobilization of antibodies on the self-assembled monolayer by antigen-binding site protection and immobilization kinetic control
}

\author{
Myungok Yoon ${ }^{1}$, Hyun Jin Hwang ${ }^{2}$, Jeong Hee Kim ${ }^{3}$
}

\footnotetext{
${ }^{1}$ Department of Chemistry, Kyung Hee University, Seoul, Korea;

${ }^{2}$ R\&D Center, Ahram Biosystems Inc., Seoul, Korea;

${ }^{3}$ Department of Oral Biochemistry, Kyung Hee University, Seoul, Korea.

Email: hjhwang@ahrambio.com, jhkimh@,khu.ac.kr
}

Received 17 January 2011; revised 23 March 2011; accepted 28 March 2011.

\begin{abstract}
The orientation of the biological molecule immobilized on a solid surface has been critical in development of various applications. In this study, orientation of antibody was retained by protecting the antigen-binding site of the antibody prior to immobilization to $\omega$-functionalized mixed self-assembled monolayer (SAM) of 12-mercaptododecanoic acid and 1-heptanethiol. More importantly, the number of immobilization bonds formed between each antigen-binding site protected antibody molecule and the solid surface was controlled by optimizing the mole fraction of the activated carboxyl group of the linker molecules in the mixed SAM. The amount of antibody used in this study was approximately equivalent to the amount for one monolayer surface coverage. The resulting activity of protected immobilized antibody was about 10 fold higher than that of random immobilized antibody.
\end{abstract}

Keywords: Antibody; Oriented Immobilization; Antigen-Binding Site Protection;

Self-Assembled Monolayer; Kinetic Control

\section{INTRODUCTION}

Interests in the efficient immobilizations of biomolecules such as enzymes, proteins, antibodies, and DNA [1-6] on the solid surfaces for biomedical and biotechnological applications have rapidly increased during the last two decades. Immunoassays, affinity chromatography, and DNA microarray $[3,7,8]$ are all based on the immobilization of biomolecules on the solid phases for the purpose of clinical diagnostics, food industry and environmental monitoring [9-11]. Widely used methods for the attachment of antibodies to solid surfaces are physical adsorp- tion, covalent coupling, cross-linking, or entrapment in a gel network [4,12-14]. However, since these methods may result in decreased binding activity and selectivity of the antibodies after immobilization due to improper orientations, or denaturing of the antibodies, much effort have been recently put in the development of site-specific immobilization of antibodies [3,15-18]. Among these are immobilizing protein $\mathrm{A}$ or $\mathrm{G}$ first to the solid surface followed by immobilization of antibodies [16,19]. In another method, azobenzene-containing polymers were used to control antibody orientation [20]. It was reported that the antigen-binding activities of immobilized Fab' fragments of rabbit anti-human $\mathrm{IgG}$ with proper orientation were more than 2 fold increase than those with random orientation [15].

In this study, in order to maximize the natural biological activity of an antibody after immobilization, the antigen-binding sites of the antibody were protected by incubating with its own antigen prior to immobilization. More importantly, the number of chemical bond formed between the antigen-binding site-protected antibody and the solid surface was optimized by kinetic control of the immobilization reaction (protected immobilization, PIM). The resulting activity of the antigen-binding site protected immobilized antibody was significantly increased compared to that of randomly immobilized antibody.

\section{MATERIALS AND METHODS}

\subsection{Chemicals and Reagents}

Chemicals for immobilization reaction are purchased from the following sources; (D,L)-thioctic acid (Aldrich, USA), 1-ethyl-3-[3-(dimethylamino)propyl]carbamide (EDC) (Sigma, USA), and $N$-hydroxysulfosuccinimide (sulfoNHS) (Pierce, USA). Au-coated slides were purchased from EMF, USA. Mouse anti-DNA monoclonal antibody (IgM) recognizes both single- and double-stranded DNA 
was obtained from Roche Diagnostics, Germany. Taq polymerase, and deoxy nucleotide mixture (dNTP) were obtained from Takara, Japan. $\left[\alpha-{ }^{35} \mathrm{~S}\right]$ d-ATP $(1250 \mathrm{Ci} /$ mmole) and scintillation cocktail solution were purchased from NEN and ICN, USA, respectively. Universal and reverse primers were synthesized from Bioneer, Korea. Other chemicals were purchased from Sigma, USA, or from other common sources.

\subsection{Formation of the Mixed SAM on the Au Surface}

Au-coated glass slides $(3 \mathrm{~mm} \times 5 \mathrm{~mm})$ were carefully cleaned with Piranha solution $\left(30 \% \mathrm{H}_{2} \mathrm{O}_{2}\right.$ : Concentrated $\mathrm{H}_{2} \mathrm{SO}_{4}=1: 3$ ) for $15-30 \mathrm{sec}$ and rinsed with $\mathrm{d}-\mathrm{H}_{2} \mathrm{O}$ and then ethanol. The cleaned bare Au surface was soaked in $10 \mathrm{mM}$ thioctic acid in ethanol for overnight rinsed with ethanol and dried. Mixed solution of 12-mercaptododecanoic acid [ $\left.\mathrm{HS}\left(\mathrm{CH}_{2}\right)_{11} \mathrm{COOH}\right]$ and 1-heptanethiol [HS$\left.\left(\mathrm{CH}_{2}\right)_{6} \mathrm{CH}_{3}\right]$ was prepared in ethanol. Au-coated glass slides were incubated with the mixed SAM solution for $1 \mathrm{hr}$ at room temperature and then rinsed with ethanol. The thiol groups were chemically adsorbed to the $\mathrm{Au}$ surface, thereby creating a mixed monolayer of 12-mercaptododecanoic acid and 1-heptanethiol. Then, Aucoated glass slides were immersed in $5 \mathrm{mM}$ sulfo-NHS and $10 \mathrm{mM}$ EDC in MES buffer ( $\mathrm{pH} \mathrm{6.0)}$ ) for $1 \mathrm{hr}$ to activate the carboxyl groups on the surface and rinsed with ethanol.

\subsection{Radioactive Labeling of DNA by Polymerase Chain Reaction (PCR)}

Bacterial plasmid DNA, pBluescriptII $\mathrm{KS}(+)$ was used as a template DNA. Concentration of DNA was measured by UV spectrophotometer (Pharmacia Biotech Ultraspec 2000, USA). A typical polymerase chain reaction (PCR) mixture contained $200 \mathrm{ng}$ of DNA, $0.4 \mu \mathrm{M}$ each of universal and reverse primer, $50 \mu \mathrm{M}$ of dNTP, $2.5 \mathrm{U}$ of Taq polymerase and 0.1 vol. of $10 \mathrm{x}$ buffer in $100 \mu \mathrm{l}$ final volume. For labeling purpose, $2 \mu \mathrm{l}$ of $\left[\alpha-{ }^{35} \mathrm{~S}\right] \mathrm{d}-$ ATP was added to the reaction mixture. The reaction mixture was heated to $94^{\circ} \mathrm{C}$ for $5 \mathrm{~min}$. The PCR profile was $94^{\circ} \mathrm{C}$ for $30 \mathrm{sec}, 50^{\circ} \mathrm{C}$ for $1 \mathrm{~min}$, and $72^{\circ} \mathrm{C}$ for $30 \mathrm{sec}$ for 30 cycles, followed by $72^{\circ} \mathrm{C}$ for $10 \mathrm{~min}$. We always ran labeling reactions with the non-labeled standard control reaction side by side. After PCR, an aliquot of the control reaction was analyzed on $1.2 \%$ agarose gel containing $0.5 \mu \mathrm{g} / \mathrm{ml}$ ethidium bromide to confirm the generation of PCR product.

\subsection{Immobilization of Anti-DNA Antibody and Immunoassay}

In order to prepare protected antibody-DNA solution, approximately $0.54 \mathrm{pmol}$ of anti-DNA antibody was incubated with approximately $1.07 \mathrm{pmol}$ of labeled DNA for $1 \mathrm{hr}$ at $37^{\circ} \mathrm{C}$ in $0.1 \mathrm{M}$ phosphate buffer ( $\mathrm{pH} 7.4$ ). Otherwise the concentration of antibody and DNA were indicated in the text. The activated Au surface was incubated with protected Antibody-DNA solution for $30 \mathrm{~min}$ at $37^{\circ} \mathrm{C}$, rinsed with a buffer of $1.0 \mathrm{M}$ potassium phosphate, $\mathrm{pH}$ 6.7. Randomly immobilized antibody was prepared by the same procedure described above except the incubation with labeled DNA. The antibody immobilized Au-coated glass slides were incubated with approximately $2.0 \mathrm{pmol}$ of labeled DNA for $2 \mathrm{hrs}$ at RT and then washed with TBST (20 mM Tris, $\mathrm{pH} 7.8,150$ $\mathrm{mM} \mathrm{NaCl}$, and $0.05 \%$ Tween-20) buffer three times. The glass slides were dried and the $\beta$-emission was measured with a scintillation counter (Wallac, system 1400, EG\&G Co., Finland).

\section{RESULTS AND DISCUSSION}

\subsection{Experimental Scheme}

Immobilization scheme of anti-DNA antibody is shown in Figure 1. In this experiment, $\mathrm{Au}$ surface was chosen as a solid phase since it has an advantage over polysac-

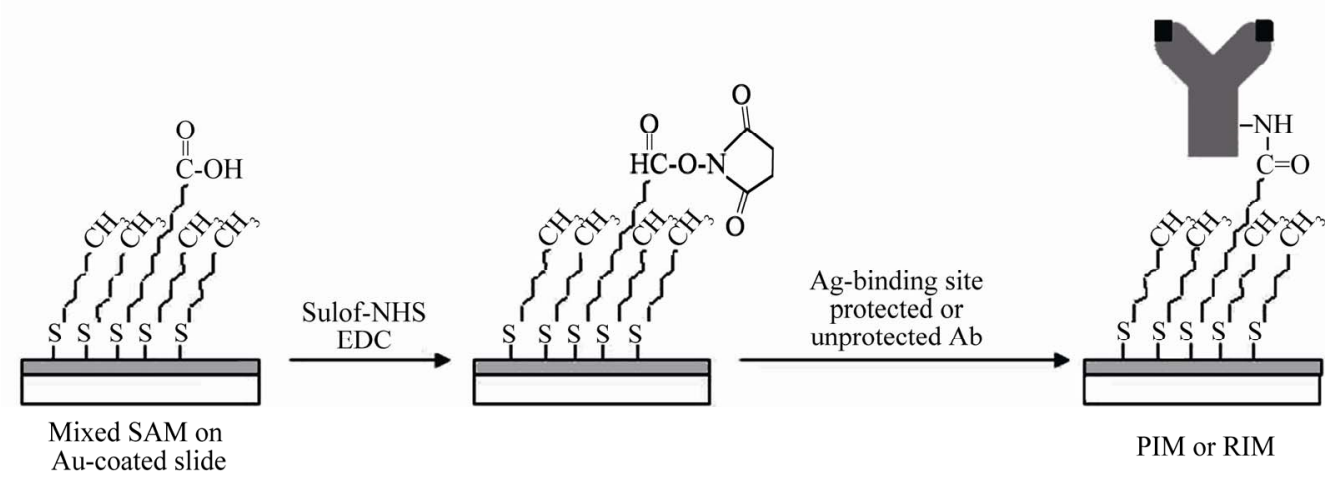

Figure 1. Schematic representation of the steps of anti-DNA antibody immobilization to the mixed SAM on Au surface. PIM; protected immobilization, RIM; random immobilization. 
charides, polystyrene or silica which are most frequently used solid phases for the immobilization of antibodies; thiols form self-assembled monolayers (SAM) on $\mathrm{Au}$ surface spontaneously due to the formation of strong Au-S covalent bonds [15,21,22], which make follow-up reactions for modification of the surface functional groups easier. The mixed monolayer of 12-mercaptododecanoic acid $\left[\mathrm{HS}\left(\mathrm{CH}_{2}\right)_{11} \mathrm{COOH}\right]$ and 1-heptanethiol $\left[\mathrm{HS}\left(\mathrm{CH}_{2}\right)_{6}{ }^{-}\right.$ $\mathrm{CH}_{3}$ ] on $\mathrm{Au}$ surface was used in this work. Surface carboxyl groups on the SAM were activated using 1-ethyl -3(3-dimethylaminopropyl)carbodiimide (EDC) and sulfo$N$-hydroxysuccinimide (sulfo-NHS) to form sulfo-NHS esters. This coupling reaction was performed in 2-(Nmorpholino)ethane sulfonic acid (MES) buffer at pH 6.0 since it is reported that sulfo-NHS ester has longer lifetime at lower $\mathrm{pH}$ [23]. Then, anti-DNA antibodies were reacted to be immobilized to the $\omega$-functionalized SAM through amide bonds.

In order to preserve the natural activity of the antibody after immobilization, the antigen-binding site of antibody were protected before immobilization to the $\mathrm{Au}$ surface by reactions with its antigen, DNA first to form antigen-antibody complexes followed by the reactions with sulfo-NHS esters (Protected immobilization, PIM). By this way the active sites are excluded from the subsequent immobilization reaction, thus contribute for the antibody to retain the proper orientation after immobilization. For random immobilization (RIM), antibody was immobilized as described above without protection of the antigen-binding sites of the antibody.

\subsection{Kinetic Control and Protection of Antigen-Binding Site Increased the Activity of Immobilized Antibody}

We used the immobilization scheme presented in Figure 1 to immobilize antibodies on the SAM formed on $\mathrm{Au}$ surface. Before immobilization, the amount of the antibody required to cover the $\mathrm{Au}$ surface to a monolayer was calculated and approximately 0.54 pmol of antiDNA antibody was used. The number of surface carboxyl group involved in the cross-linking of the antibody to the SMA was also considered. Due to the steric requirement of large bio-molecules, high concentration of surface carboxyl group was found to rather decrease the activity of immobilized biomolecule [24]. Therefore, considering the size of anti-DNA antibody $(8.5 \mathrm{~nm} \times$ $14.5 \mathrm{~nm}$ ) [2], mixed monolayer of 12-mercaptododecanoic acid and 1-heptanethiol was employed in our experiment instead of using pure monolayer of 12-mercaptododecanoic acid. Therefore, by controlling the mole fraction of 12-mercaptododecanoic acid in the SAM, the number of the carboxyl group involved in the immobilization of antibodies can be controlled, subsequently the number of antibody immobilized on the surface is controlled.

In order to protect the antigen-binding site of the antibody, a 65 bp double stranded DNA (ds-DNA) labeled with ${ }^{35} \mathrm{~S}$ was prepared by polymerase chain reaction (PCR) and about 1.07 pmole of the labeled ds-DNA was used for protection of the two antigen-binding sites in each antibody (Antibody:DNA $\approx 1: 2$ ). For RIM, preincubation of the antibody with the labeled DNA step was excluded. After immobilization, glass slides were incubated with its labeled form of antigen, ${ }^{35}$ S-labeled dsDNA. The activities of the immobilized antibodies were measured by counting $\beta$-emission from antigen-antibody complexes which were formed by incubating immobilized antibodies with ${ }^{35} \mathrm{~S}$-labeled DNA. Radioimmunoassay is very sensitive to a very small amount of ${ }^{35} \mathrm{~S}$ labeled DNA, thus enables us to measure a very small amount of immobilized antibody on the surface.

The concentration of carboxyl group in the SAM was varied from $0 \%$ to $100 \%$ and the activity of immobilized antibody was measured as described above. The PIM antibodies preserved their activity much better than the RIM antibodies resulting $\beta$-emission from these films are larger throughout the carboxyl group ratio used in this study (Figure 2(a)). It is very interesting to note that the maximum activities of immobilized antibodies occur at low surface carboxyl concentration of 5\% (Figures 2 (a) and (b)). The activity of the immobilized antibodies by PIM method at 5\% of carboxyl group was approximately 10 times higher than the activity of RIM antibody (Figure 2(b)).

In this experiment we labeled PIM antibodies with ${ }^{35} \mathrm{~S}$ and then immobilization was performed. After these treatments, part of antibodies would lose their activity through kinds of modifications or other unknown mechanisms. If antibodies have been labeled by ${ }^{35} \mathrm{~S}$, isotopes on inactivated antibodies would not be all released from the Au surface, causing false conclusions. However, it seems that these effects are negligible when we compared the radioactivity acquired from pre-labeled PIM antibodies and not pre-labeled RIM antibodies at higher concentration of carboxyl group (25\% - 100\%) which showed very low radioactivity in both PIM and RIM antibodies (Figure 2(a)).

In the coupling reaction of antibody with sulfo-NHS ester, either the amino group on the Fc region of the antibody, or the one on the Fab' fragment near the antigen-binding site can react to form an amide bond; the former will preserve the native structure of the antibody and the latter may lose the native structure of the antibody. When the antibody was reacted randomly, it was found that control over the orientation of the immobilized antibody was difficult, and this random orientation 


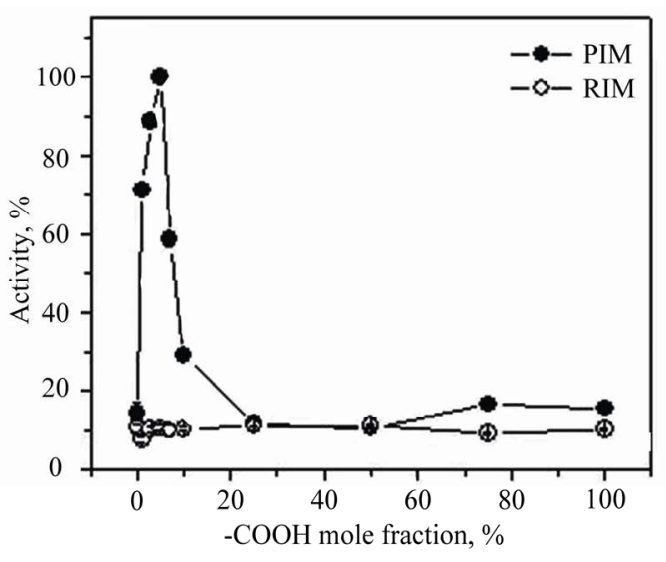

(a)

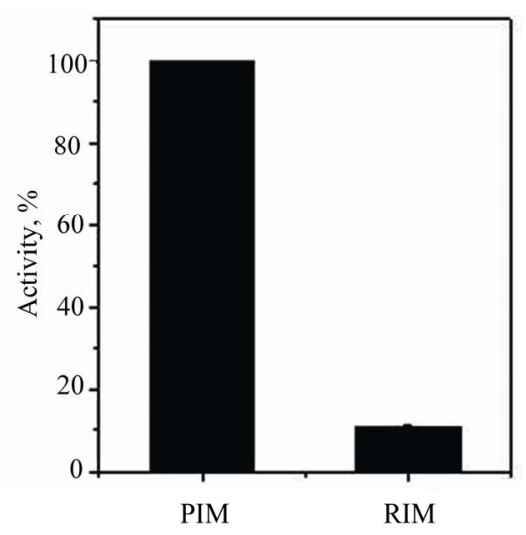

(b)

Figure 2. The activity of immobilized anti-DNA antibody to the mixed SAM on Au surface. The activities of immobilized antibodies by PIM method (•) or RIM method ( $(\circ)$ were obtained as a function of the mole fraction of 12-mercaptododecanoic acid (a). The activity of the immobilized antibody either by PIM or RIM method at 5\% of 12-mercaptododecanoic acid was compared (b). A mixed SAM of 12-mercaptododecanoic acid and 1-hepthanethiol was used to introduce the carboxyl groups as the reactive group for immobilization. The protection ratio of antibody to antigen was 1:2.

of the antibody results in the loss of the activity of the immobilized antibody. However, when the antigen binding sites of the antibody were protected before immobilization, the activity of the PIM antibody was significantly increased compared to that of RIM antibody resulting $\beta$-emission from these films are much larger as shown in Figure 2.

In addition to the protection of antigen-binding sites, the increased activity at lower carboxyl group concentration can be explained in terms of number of bonds formed between antibody and the supporting surface. Since there are multiple reaction groups exist on the surface of the antibody as well as the supporting surface, multiple immobilization bonds can be formed between the antibody and the supporting surface. Such non-specific formation of multiple bonds in various region of the antibody can induce structural change and destruction of the biologically active molecule upon immobilization, thereby causing substantial reduction of the antigenbinding activity of the antibody. It seems that it is critical to minimize the number of bonds formed between the antibody and the surface. Our results revealed that about $5 \%$ of 12-mercaptododecnoic acid is appropriate to form a minimal number of covalent bond between the antibody and the surface (Figure 2(a)). At higher concentration of carboxyl groups, where multiple immobilization bonds were expected to formed, the activity of PIM antibody was dramatically reduced and it was similar to that of RIM antibody. This observation supports that the multiple bond formation cause the destruction of antibody's natural structure.

Considering the maximum density of thiol groups on
$\mathrm{Au}$ is about $0.5 \mathrm{~nm}[21,25]$, there will be about $100-200$ thiol molecules under the antibody to be immobilized. Since our results showed the maximum activity of the immobilized antibody was acquired with about $5 \%$ of reactive group in the SAM on the Au surface. Theoretically, $5 \%$ of the reactive group can produce at maximum of 5 immobilization bonds. Considering that in many available reaction conditions, especially in aqueous solution, the reaction probability of the reaction group is substantially lower than $100 \%$. Therefore, our results suggest that it is likely that only 1 immobilization bond or at most a few bonds are formed between the antibody and the SAM.

\subsection{Activity of Immobilized Antibody as a Function of the Concentration of the Antibody Used and the Protection Ratio}

We prepared different amount of antibodies ranged from 0.07 pmol to 0.68 pmol which is sub- to near-monolayer concentration of antibody. Prepared antibodies were antigen-binding site protected and immobilized on Au surface as described above. The mole fraction of the 12mercaptododecanoic acid used to introduce carboxyl reaction group on the Au surface with respect to the total moles of the thiol molecules was $5 \%$. The activity of the immobilized antibody was compared and plotted. As shown in Figure 3, the activity of immobilized antibody was linearly proportional to the concentration of antibody used in this experiment.

The activity of the immobilized anti-DNA antibody was measured at different protection ratio from 1: 0.0625 to $1: 4$ (Figure 4). The mole fraction of the 


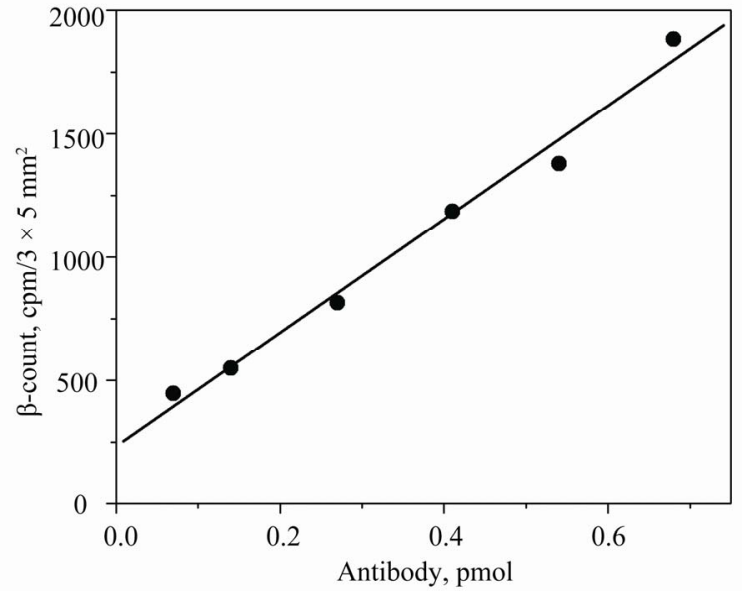

Figure 3. Antibody concentration dependence of the activity of antigen-binding site protected antibody after immobilization to Au-coated slide glass. The concentration of antibody used was from sub- to near-monolayer to cover the immobilization surface. PIM method was used at $5 \%$ of 12 -mercaptododecanoic acid. The ratio of anti-DNA antibody to DNA was 1:2. Radioactivity of PIM antibody on Au surface $\left(3 \times 5 \mathrm{~mm}^{2}\right)$ was measured and plotted.

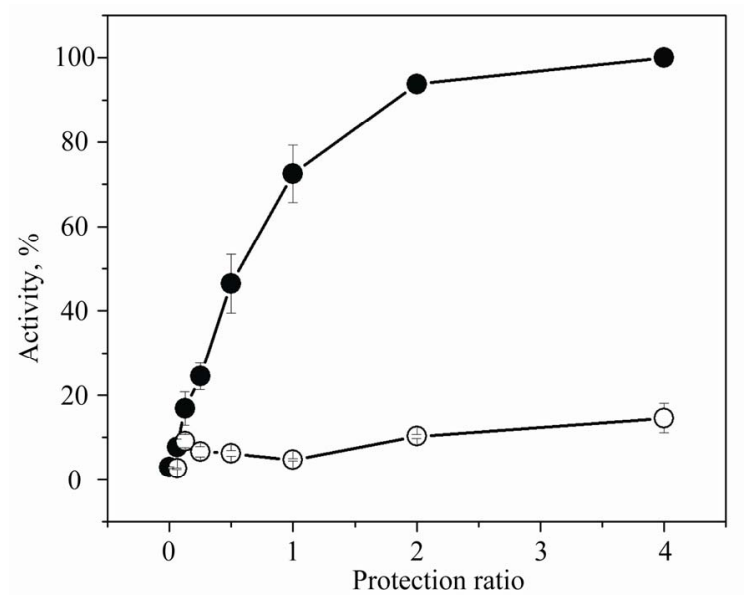

Figure 4. The activity of antibody immobilized to the SAM on Au surface as a function of antigen-binding site protection ratio. The antibody concentration was 0.54 pmol and the protection ratio of anti-DNA antibody to DNA was ranged from 1:0.0625 to 1:4. The activity of immobilized antibodies by PIM method $(\bullet)$ or RIM method ( $($ ) were depicted.

12-mercaptododecanoic acid in the SAM was 5\%. The activity of the immobilized antibody was increased as the protection ratio increased. PIM antibodies revealed much higher binding activity compared to RIM antibodies throughout the protection ratio used in this experiment. The saturation phenomenon was observed in the PIM case when the molar ratio of the anti-DNA antibody to the ds-DNA used for protection was in the range of
$1: 1 \sim 1: 2$. Since there are two antigen-binding sites for each antibody, it is very reasonable that the binding activity of immobilized antibody reaches maximum when the protection ratio increased from 1 to 2 . This data support the previous results described above that the antigen-binding sites were protected by formation of the antigen-antibody complex.

In conclusion, we report on the development of a novel method to immobilize an antibody on the solid surface by using a PIM method and kinetically controlling the number of chemical bond formed between the protected antibody and the solid surface. The resulting antigen-binding activity of protected immobilized antibody was about 10 fold higher than that of random immobilized antibody. This method could have wide application in production of various bio-chips.

\section{REFERENCES}

[1] Zhen, G., Eggli, V., Vörös, J., Zammaretti, P., Textor, M., Glockshuber, R. and Kuennemann, E. (2004) Immobilization of the enzyme beta-lactamase on biotin-derivatized poly(L-lysine)-g-poly(ethylene glycol)-coated sensor chips: A study on oriented attachment and surface activity by enzyme kinetics and in situ optical sensing. Langmuir, 20, 10464-10473. doi:10.1021/la0482812

[2] Browning-Kelly, M.E., Wadu-Mesthrige, K., Hari, V. and Liu, G.Y. (1997) Atomic force microscopic study of specific antigen/antibody binding. Langmuir, 13, 343-350. doi:10.1021/la960918x

[3] Torrance, L., Ziegler, A., Pittman, H., Paterson, M., Toth, R. and Eagleston, I. (2006) Oriented immobilization of engineered single-chain antibodies to develop biosensors for virus detection. Journal of Virological Methods, 134, 164-170. doi:10.1016/j.jviromet.2005.12.012

[4] López-Gallego, F., Betancor, L., Mateo, C., Hidalgo, A., Alonso-Morales, N., Dellamora-Oritz, G., Guisan, J.M. and Fernandez-Lafuente, R. (2005) Enzyme stabilization by glutaraldehyde crosslinking of adsorbed proteins on animated supports. Journal of Biotechnology, 119, 70-75. doi:10.1016/j.jbiotec.2005.05.021

[5] Lu, B., Xie, J., Lu, C., Wu, C. and Wei, Y. (1995) Oriented immobilization of Fab' fragments on silica surfaces. Analytical Chemistry, 67, 83-87. doi:10.1021/ac00097a014

[6] Zhao, X., Nampalli, S., Serino, A.J. and Kumar, S. (2001) Immobilization of oligonucleotides with multiple anchors to microchips. Nucleic Acids Research, 29, 955-959. doi:10.1093/nar/29.4.955

[7] Markoglou, N. and Wainer, I.W. (2001) Synthesis and characterization of an immobilized phenylethanolamine $\mathrm{N}$-methyltransferase liquid chromatographic stationary phase. Analytical Biochemistry, 288, 83-88. doi:10.1006/abio.2000.4884

[8] White, K.P., Rifkin, S.A., Hurban, P. and Hogness, D.S. (1999) Microarray analysis of drosophila development during metamorphosis. Science, 286, 2179-2184. doi:10.1126/science.286.5447.2179 
[9] Ward, K. (2006) Microarray technology in obstetrics and gynecology: A guide for clinicians. American Journal of Obstetrics and Gynecology, 195, 364-372. doi:10.1016/j.ajog.2005.12.014

[10] Roy, S. and Sen, C.K. (2006) cDNA microarray screening in food safety. Toxicology, 221, 128-133. doi:10.1016/j.tox.2005.12.025

[11] Lettieri, T. (2006) Recent application of DNA microarray technology to toxicology and ectoxicology. Environmental Health Perspectives, 114, 4-9.

[12] Giacomelli, C.E., Vermeer, A.W.P. and Norde, W. (2000) Adsorption of immunoglobulin $\mathrm{G}$ on core-shell latex particles precoated with chaps. Journal of Colloid and Interface Science, 231, 283-288. doi:10.1006/jcis.2000.7159

[13] Charelier, R.C., Gengenbach T.R., Griesser, H.J., Brigham-Burke, M. and O'Shannessy, D.J. (1995) A general method to recondition and reuse BIAcore sensor chips fouled with covalently immobilized protein/peptide. Analytical Biochemistry, 229, 112-118. doi:10.1006/abio.1995.1386

[14] Charles, P.T., Goldman E.R., Rangasammy, J.G., schauer C.L., Chen, M.S. and Taitt, C.R. (2004) Fabrication and characterization of 3D hydrogel microarrays to measure antigenicity and antibody functionality for biosensor application. Biosensors and Bioelectronics, 20, 753-764. doi:10.1016/j.bios.2004.04.007

[15] Bonroy, K., Frederix, F., Reekmans, G., Dewolf, E., De Palma, R., Borghs, G., Declerck, P. and Goddeeris, B. (2006) Comparison of random and oriented immobilization of antibody fragments on mixed self-assembled monolayers. Journal of Immunological Methods, 312, 167181. doi:10.1016/j.jim.2006.03.007

[16] Tanaka, G., Funabashi, H., Mie, M. and Kobatake, E. (2006) Fabrication of an antibody microwell array with self-adhering antibody binding protein. Analytical Biochemistry, 350, 298-303. doi:10.1016/j.ab.2005.12.034

[17] Ha, T.H., Jung, S.O., Lee, J.M., Lee, K.Y., Lee, Y., Park, J.S. and Chung, B.H. (2007) Oriented immobilization of antibodies with GST-fused multiple Fc-specific B-domains on a gold surface. Analytical Chemistry, 79, 546-556. doi:10.1021/ac061639+

[18] Lo, Y.S., Nam, D.H., So, H.M., Chang, H., Kim, J.J., Kim Y.H. and Lee, J.O. (2009) Oriented-immobilization of antibody fragments in Ni-decorated single-walled carbon nanotube devices. ACS Nano, 3, 3649-3655. doi:10.1021/nn900540a

[19] Liu, F., Dubey, M., Takahashi, H., Castner, D.G. and Grainer, D.W. (2010) Immobilized antibody orientation analysis using secondary ion mass spectrometry and fluorescence imaging of affinity-generated pattern. Analytical Chemistry, 82, 2947-2958. doi:10.1021/ac902964q

[20] Mouri, M., Ikawa, T., Narita, M., Hoshino, F. and Watanabe, O. (2010) Orientation control of photo-immobilized antibodies on the surface of azobnzene-containing polymers by the introduction of functional groups. $\mathrm{Mi}$ cromolecular Bioscience, 10, 612-620.

[21] Ulman, A. (1996) Formation and structure of self-assembled monolayers. Chemical Reviews, 96, 1533-1554. doi:10.1021/cr9502357

[22] Prime, K.L. and Whitesides, G.M. (1991) Self-assembled organic monolayers: Model system for studying adsorption of proteins at surfaces. Science, 252, 1164-1167. doi:10.1126/science.252.5009.1164

[23] Grebarek, Z. and Gergely, J. (1990) Zero-length crosslinking procedure with the use of active esters. Analytical Biochemistry, 185, 131-135. doi:10.1016/0003-2697(90)90267-D

[24] Mittler-Neher, S., Spinke, J., Liley, M., Nelles, G., Weisser, M., Back, R., Wenz, G. and Knoll, W. (1995) Spectroscopic and surface-analytical characterization of selfassembled layers on $\mathrm{Au}$. Biosensors and Bioelectronics, 10, 903-916. doi:10.1016/0956-5663(95)99228-D

[25] Alves, C.A., Smith, E.L. and Porter M.D. (1992) Atomic scale imaging of alkanethiolate monolayers at gold surfaces with atomic force microscopy. Journal of the American Chemical Society, 114, 1222-1227. doi:10.1021/ja00030a015 